\title{
Infrared Laser Heating Applied to Nanopore Sensing for DNA Duplex Analysis
}

\author{
Christopher E. Angevine ${ }^{1}$, Sarah J. Seashols-Williams ${ }^{2}$ and Joseph E. Reiner ${ }^{1}$ \\ 1. Department of Physics, Virginia Commonwealth University, Richmond, VA 23284, USA \\ 2. Department of Forensic Science, Virginia Commonwealth University, Richmond, VA 23284, USA
}

\section{Supporting Information}

\section{Residence Time Distributions}

The residence time distributions for the 20 and 50-mer DNA homopolymers (polyA 20 and polyA $_{50}$ ). The smaller DNA shows a single exponential residence time distribution consistent with the polyA $\mathrm{A}_{30}$ data shown in Fig. 5 in the main text, but the 50-mer DNA exhibits a double exponential dependence. We hypothesize that the 50-mer current fluctuations give rise to a shorter time constant that most likely corresponds to the molecule not being fully confined with the nanopore volume. We note that the longer-time constants $\left(\tau_{1}\right)$ for the 50 -mer samples were used to create Fig. 6 in the main text.

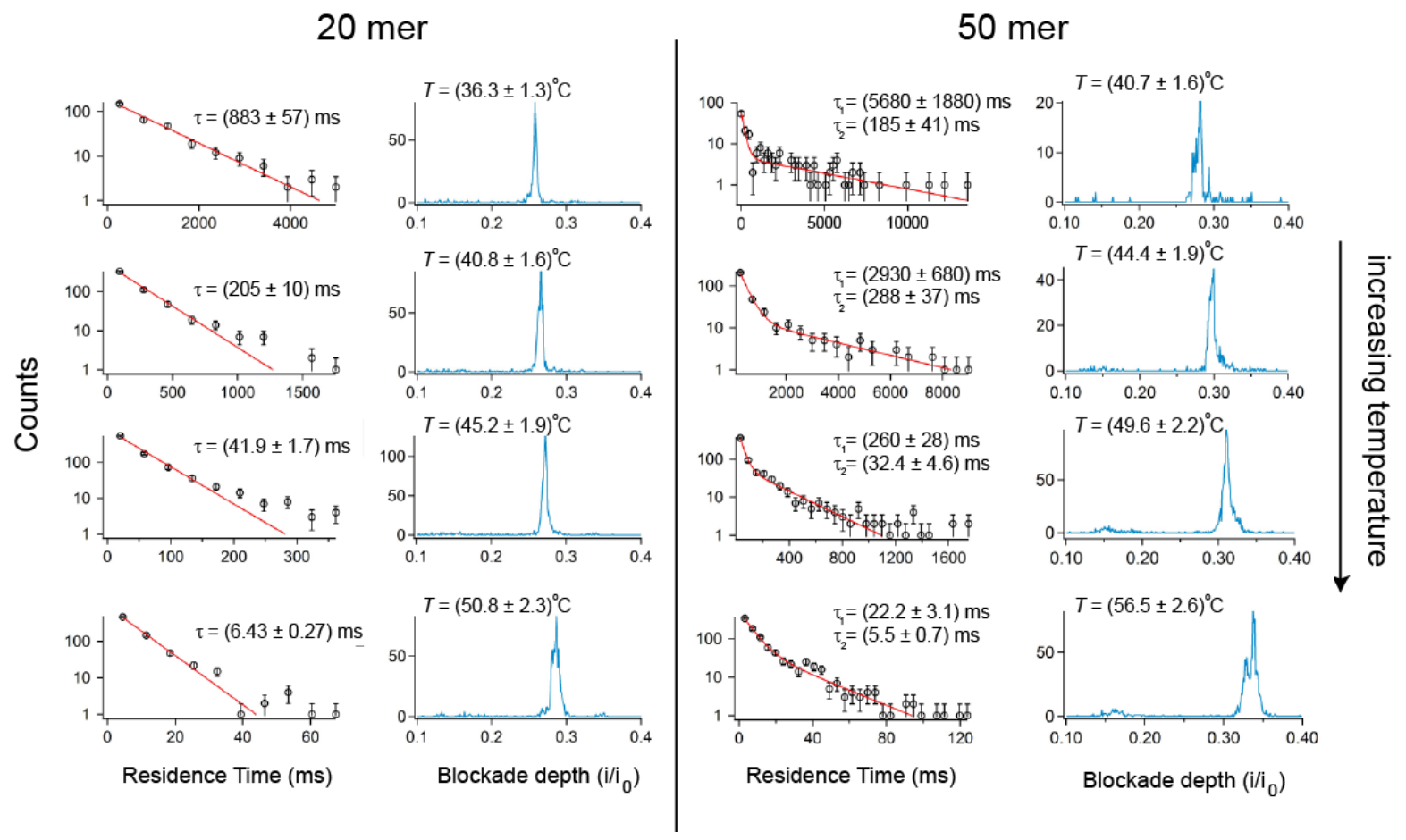

Figure S1: Residence time and current blockade distributions for poly $\mathrm{A}_{20}$ and poly $\mathrm{A}_{50}$. The residence time distributions are described by single exponential functions for poly $\mathrm{A}_{20}$, while the poly $\mathrm{A}_{50}$ exhibits a double exponential dependence. The short time constant for the 50-mer DNA most likely corresponds to the larger molecule extending outside the pore and exiting the pore. The trend shown in Fig. 6 of the main text suggests that the longer time constant corresponds to melting and transit through the pore. All data shown here taken in $1 \mathrm{M} \mathrm{KCl}$ solution under a $120 \mathrm{mV}$ applied transmembrane potential. All uncertainties and error bars correspond to \pm 1 S.D. 